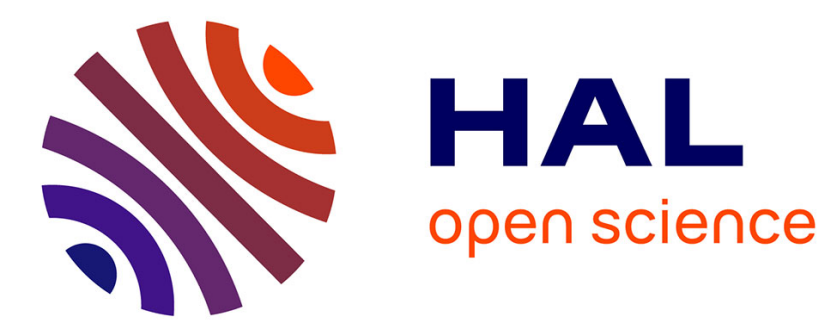

\title{
Effect of tin on the phase transformations of cast irons
}

\author{
Jacques Lacaze, Jon Sertucha
}

\section{To cite this version:}

Jacques Lacaze, Jon Sertucha. Effect of tin on the phase transformations of cast irons. Journal of Phase Equilibria and Diffusion, 2017, pp. 1-7. 10.1007/s11669-017-0561-8 . hal-01565184

\section{HAL Id: hal-01565184 \\ https://hal.science/hal-01565184}

Submitted on 19 Jul 2017

HAL is a multi-disciplinary open access archive for the deposit and dissemination of scientific research documents, whether they are published or not. The documents may come from teaching and research institutions in France or abroad, or from public or private research centers.
L'archive ouverte pluridisciplinaire HAL, est destinée au dépôt et à la diffusion de documents scientifiques de niveau recherche, publiés ou non, émanant des établissements d'enseignement et de recherche français ou étrangers, des laboratoires publics ou privés. 


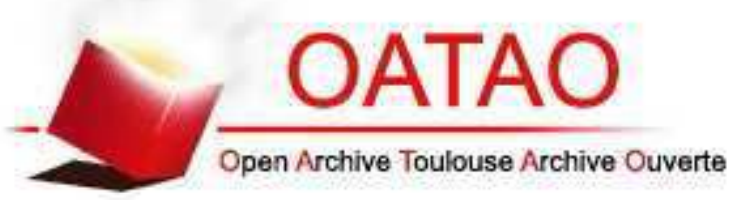

\section{Open Archive TOULOUSE Archive Ouverte (OATAO)}

OATAO is an open access repository that collects the work of Toulouse researchers and makes it freely available over the web where possible.

This is an author-deposited version published in : http://oatao.univ-toulouse.fr/ Eprints ID : 18080

To link to this article : DOI: $10.1007 / \mathrm{s} 11669-017-0561-8$

URL : http://dx.doi.org/10.1007/s11669-017-0561-8

To cite this version : Lacaze, Jacques and Sertucha, Jon Effect of tin on the phase transformations of cast irons. (2017) Journal of Phase Equilibria and Diffusion. pp. 1-7. ISSN 1547-7037

Any correspondence concerning this service should be sent to the repository administrator: staff-oatao@ listes-diff.inp-toulouse.fr 


\title{
Effect of Tin on the Phase Transformations of Cast Irons
}

\author{
Jacques Lacaze $^{1} \cdot$ Jon Sertucha $^{2}$
}

\begin{abstract}
Copper, manganese and essentially tin are used as alloying elements for obtaining cast irons with a fully pearlitic matrix in the as-cast state. Addition of tin, at a level of about $0.10-0.15$ mass $\%$, seems to be the only practical way for avoiding growth of ferrite in the stable eutectoid reaction and to fully transform the matrix of the material to pearlite in the metastable eutectoid system. While the role of copper and manganese has been previously rationalized, the way tin affects the eutectoid transformation in cast irons is still a matter of debate. The present work makes use of an assessment of the Fe-Sn system and of experimental data in the $\mathrm{Fe}-\mathrm{C}-\mathrm{Sn}$ system to evaluate the effect of tin on phase equilibria in this latter system. One ternary parameter is estimated and the resulting modification is applied to literature data on Fe-C$\mathrm{Si}-\mathrm{Sn}$ equilibria. Finally, solid-state phase transformation temperatures are calculated and used to discuss experimental information dealing with pearlitic cast irons. It is proposed that pearlite formation in Sn-bearing cast irons is associated to the transient formation of a $\mathrm{Fe}_{3} \mathrm{SnC}$ compound which has an ordered FCC structure.
\end{abstract}

Keywords cast iron ${ }^{\circ}$ eutectoid transformation ${ }^{\circ} \mathrm{Fe}-\mathrm{C}-\mathrm{Sn}$ system

\footnotetext{
\& Jacques Lacaze

jacques.lacaze@ensiacet.fr

Jon Sertucha

jsertucha@azterlan.es

1 CIRIMAT, ENSIACET, Université de Toulouse, CS 44362, 31030 Toulouse Cedex 4, France

2 Ingeniería, I ? D y Procesos de Fundición, IK4-Azterlan, 48200 Durango, Bizkaia, Spain
}

\section{Introduction}

Common cast irons are $\mathrm{Fe}-\mathrm{C}-\mathrm{Si}$ alloys of near eutectic composition, meaning typically $2-4$ mass $\% \mathrm{Si}$ and 3.8-3.2 mass\% C. Cast irons with lamellar graphite (LGI) are most often intended to have a pearlitic matrix that will give them a high strength which will somehow compensate for their intrinsic low ductility. On the contrary, cast irons with spheroidal graphite (SGI) are cast for either a fully ferritic matrix, associated with a high fatigue resistance and a high ductility, or a fully pearlitic matrix which will ensure high tensile strength to the expense of lower ductility. In all practicality, a fully ferritic matrix will be obtained by slow cooling during the eutectoid transformation in the stable (Fe)-graphite system, while a pearlitic matrix will be favored by increasing the cooling rate which will ease the solid-state transformation in the metastable $(\mathrm{Fe})$-cementite system.

When the casting conditions are fixed by production constraints, strict control of low level elements such as manganese and copper is used to favor a final ferritic matrix while addition of these elements helps getting a pearlitic matrix. However, it is recognized that addition of these two elements is generally not sufficient to get a fully pearlitic matrix ${ }^{[1]}$ and it is usual to add some tin or some antimony to this aim. Previous work has shown that a tin equivalent $\mathrm{Sn}_{\mathrm{eq}}$ could be defined as ${ }^{[2,3]}$ :

$\mathrm{Sn}_{\text {eq }} 1 / 4$ 0:075 ${ }^{\circ}$ w $_{\text {Mn }}$ p 0:125 ${ }^{\circ}$ w $_{\text {Cu }}$ p w w $_{\text {n }}$

ðEq 1P

where $\mathrm{w}_{\mathrm{i}}$ is the amount in mass\% of the alloying element $\mathrm{i}$. When $\mathrm{Sn}_{\text {eq }}$ is higher than about 0.13 mass\%, a fully pearlitic structure is obtained in spheroidal graphite cast irons for casting conditions corresponding to the standard thermal analysis cup used for melt control before pouring. 
Equation 1 shows that the pearlite promoter effect of copper or manganese is about 10 times lower than that of tin which indicates that these elements may affect the eutectoid transformation in a different way than tin. It has been suggested that the role of manganese is to strongly decrease the driving force for the stable eutectoid transformation, while that of copper is to decrease the transformation temperature below the ferrite Curie temperature at which the carbon diffusion coefficient in ferrite abruptly decreases. ${ }^{[4,5]}$

The role of tin is controversial, with Johnson and Kovacs $^{[6]}$ and Kovacs ${ }^{[7]}$ reporting enrichment in tin at the graphite matrix interface, while others could not find it. Such an enrichment could lead to the formation of Snbearing cementite as proposed by Grigorovich ${ }^{[8]}$ which however goes against the experimental knowledge that $\mathrm{Sn}$ does not promote cementite during solidification even when added at a level of 0.5 mass $\% .{ }^{[9]}$ Also, Kovacs ${ }^{[7]}$ stressed that such an enrichment could not be detected in the lamellar iron he studied in which Sn had been added at similar levels as in the nodular irons and was pearlite promoter as well. This adds to the controversy as there is no reason for tin segregating differently in lamellar and spheroidal graphite irons. One of the reasons that may explain that this controversy is still under debate is that no data on the effect of tin on the stable and metastable eutectoid temperatures has been made available until now.

The present work is thus divided in two parts. The first one presents step by step phase diagram calculations performed to predict the effect of tin on phase equilibria in the Fe-rich corner of the Fe-C-Si-Sn system. These calculations are then used for discussing previous experimental data on the effect of tin on stable and metastable transformation temperatures of common cast irons.

\section{Thermodynamic Description of the Fe-rich Corner of the Fe-C-Sn System}

The thermodynamic evaluation of the Fe-Sn phase diagram by Kumar et al. ${ }^{[10]}$ has been introduced in the SSOL databank that was available in 1998. The only change made to this latter bank is the improvement of the Fe-C-Si system performed by Miettinen ${ }^{[11]}$ to the earlier assessment by Lacaze and Sundman. ${ }^{[12]}$ Following usual practice, interaction parameters identical to those of the BCC_A2 phase were introduced in the description of the HCP_A3 phase to avoid the stabilization of the latter in the Fe-Sn system. Also, the expression of the stability of FCC-Sn relative to the standard state BCT-Sn selected by Kumar et al. ${ }^{[10]}$ was accepted and writes $(\mathrm{J} / \mathrm{mol})$ :

${ }^{0} \mathrm{G}_{\mathrm{Sn}}^{\mathrm{FCC}}-{ }^{0} \mathrm{G}_{\mathrm{Sn}}^{\mathrm{BCT}} 1 / 4 \mathrm{p} 5510-8: 46^{\circ} \mathrm{T}$

ðЕq2P
Even though the present study focuses only on the Ferich corner of the system, there is unfortunately very little experimental information for assessing the description obtained by extrapolating the binary systems. In particular, there is a known $\mathrm{Fe}_{3} \mathrm{SnC}$ compound with a perovskite structure $^{[13]}$ that should be accounted for but for which no thermodynamic or phase diagram information was found. Such a phase that has an ordered FCC structure appears in several systems as established for a long time. ${ }^{[14]}$ The $\mathrm{Fe}_{3} \mathrm{AlC}$ phase has been previously described by means of a CALPHAD approach with a four-sublattice model in the case of the Fe-Al-C system ${ }^{[15]}$ but such a complex modelling was considered out of the scope of the present work because of the very low tin contents relevant for applications to cast irons.

Wang Zhengyue et al. ${ }^{[16]}$ measured carbon solubility limits in Fe-C-Sn liquid at various temperatures for tin contents up to 3.5 mass\%. Figure 1 shows this experimental information plotted against the calculations made using the SSOL database without introducing any interaction term between $\mathrm{C}$ and $\mathrm{Sn}$ in the liquid. It is seen that, apart for a clear shift of the carbon content in the binary FeC system $\left(\mathrm{w}_{\mathrm{Sn}}=0\right)$ which then translates into the ternary system, the effect of tin on the solubility limit of carbon is well represented at each investigated temperature without resorting to any interaction coefficient.

Equilibrium between austenite and liquid in the iron-rich corner of the Fe-C-Sn system has been studied by Imai et al. $^{[17]}$ at different temperatures for various $\mathrm{Fe}-\mathrm{C}-\mathrm{Sn}$ alloys and at $1443 \mathrm{~K}$ for apparently one single alloy on which experiments were repeated. To reproduce the distribution of tin between austenite and liquid at $1443 \mathrm{~K}$, it

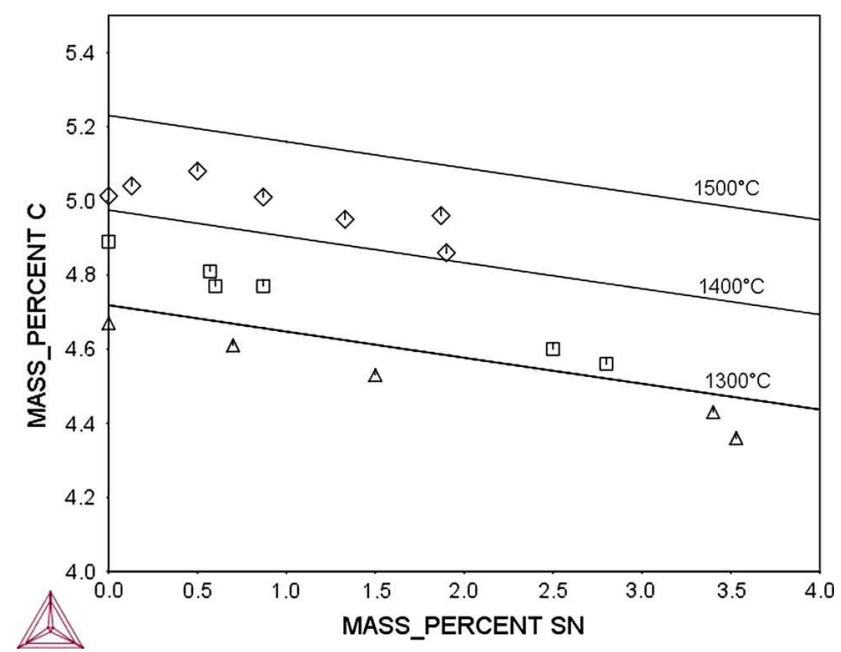

Fig. 1 Comparison of experimental carbon solubility limit ${ }^{[16]}$ with calculations. Diamonds, squares and triangles are for experimental data obtained at 1500,1400 and $1300 \mathrm{oC}$ respectively 
was necessary to add a ternary interaction parameter for austenite. Its value was finally set by trial and error to:

LðFCC A1; Fe; Sn : C; OP 1/4-150;000 J/mol ðEq3P

Figure 2 shows the calculated isothermal section at $1443 \mathrm{~K}$ of the Fe-rich corner with a comparison of the calculated tie-lines for equilibrium between austenite and liquid with the experimental results. Though a similar shift in carbon content as in Fig. 1 can be observed, the slope of the experimental and calculated tie-lines agree. Without the interaction term, the partition coefficient which is close to 0.70 for composition expressed in atom fraction would have been much lower at 0.22 .

In Table 1 are compared the experimental and calculated tin partition coefficients between austenite and liquid, $\mathrm{k}_{\mathrm{S}}^{\mathrm{c} / \mathrm{L}}$, for the various alloys and temperatures investigated by Imai et $\mathrm{al}^{\left[{ }^{[17]}\right.}$ here on the basis of compositions expressed in mass and not in atom fraction. The carbon content of the alloys has sometimes been decreased, as indicated in the notes in the table, to achieve a two-phase calculation. It is seen that the temperature effect is perfectly reproduced when using the constant interaction term given by Eq 3 .

Similar calculations with comparison to experimental results from Tanaka ${ }^{[18]}$ for $\mathrm{Fe}-\mathrm{C}-\mathrm{Sn}$ and $\mathrm{Fe}-\mathrm{C}-\mathrm{Si}$-Sn alloys ace reported in Table 2 2yith only the tin partition ciefficient, $\mathrm{k}_{\mathrm{Sn}}$, ${ }_{\mathrm{Si}}$, partition coefficients for quaternary alloys. To achieve a two phase austenite-liquid equilibrium, either the temperature or the carbon content of the alloy was slightly modified in some cases, as indicated in the notes of the table. On the whole, a very good agreement between calculations and experiments is observed. For the Fe-C-Si-Sn alloys at the two highest

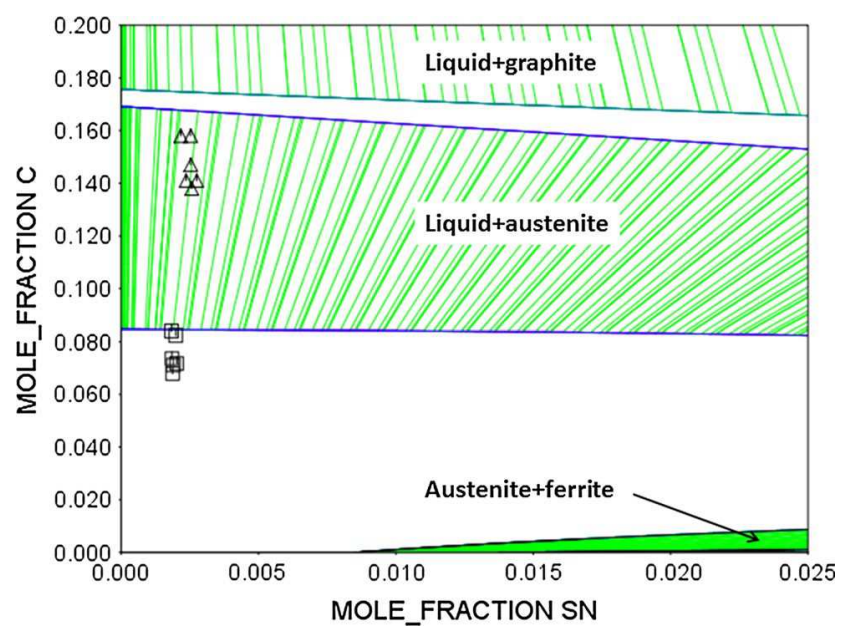

Fig. 2 Calculated isothermal section of the Fe-rich corner of the FeC-Sn phase diagram at $1443 \mathrm{~K}$ compared to experimental austenite/ liquid equilibrium data ${ }^{[17]}$ (squares for liquid composition and triangles for austenite composition). Two-phase domains with tielines are identified
Table 1 Experimental tin partition coefficient $\mathrm{k}_{\mathrm{Sn}}^{\mathrm{c} / \mathrm{L}}$ for equilibrium between austenite $\mathrm{c}$ and liquid $\mathrm{L}$ for various Fe-C-Sn alloys (compositions in mass \% $)^{[17]}$ and corresponding calculated values

\begin{tabular}{lccc}
\hline Alloy & $\begin{array}{c}\text { Holding } \\
\text { temperature, } \mathrm{K}\end{array}$ & Experimental & Calculated \\
\hline Fe-1.71C-0.76Sn (a) & 1676 & 0.28 & 0.24 \\
Fe-2.42C-1.64Sn (b) & 1613 & 0.37 & 0.30 \\
Fe-2.91C-1.03Sn (c) & 1586 & 0.42 & 0.34 \\
Fe-2.72C-0.52Sn & 1573 & 0.41 & 0.35 \\
Fe-3.26C-0.46Sn & 1523 & 0.49 & 0.44 \\
Fe-3.58C-1.1Sn & 1485 & 0.63 & 0.52 \\
Fe-3.77C-0.43Sn & 1443 & 0.73 & 0.65 \\
Fe-4.02C-1.66Sn (d) & 1418 & 0.84 & 0.71 \\
\hline
\end{tabular}

For calculation, the carbon content was set to 1.51 mass\% (a), 2.22 mass\% (b) and 2.51 mass\% (c) respectively for the composition to be in the calculated two-phase austenite/liquid field, $d$ the calculation temperature was raised to $1423 \mathrm{~K}$ for liquid to be present

temperatures, the experimental silicon partition coefficient is slightly higher than 1 while calculations predict this element behaves as in steels, with a partition coefficient slightly below 1 .

\section{Application to Cast Irons}

With the above description of the Fe-rich corner of the Fe$\mathrm{C}-\mathrm{Sn}$ system, and owing to the very limited amount of tin relevant for cast irons production (0.1-0.13 mass\% at most), it could be considered that appropriate calculations for Fe-C-Si-Sn alloys could be performed.

It was found that, for an alloy containing 2.5 mass $\% \mathrm{Si}$, the addition of 1 mass \% Sn would decrease the eutectic temperature by $2 \mathrm{oC}$ and decrease the corresponding eutectic carbon content from 3.6 to 3.5 mass\%. This effect on the eutectic temperature is so small that it would hardly be observed experimentally, as seen with the results by Lacaze et al. ${ }^{[2]}$ who reported that $\mathrm{Sn}$ addition showed either an increase or a decrease of the eutectic plateau temperature as recorded by thermal analysis. The calculated decrease is however in agreement with results reported by Kanno et al. ${ }^{[19]}$

The most important information expected from the above description concerns the eutectoid transformation. Figure 3 and 4 compare isopleth $\mathrm{Fe}-\mathrm{C}$ sections of, respectively, the stable and metastable systems at 2.5 mass $\% \mathrm{Si}$ and 0 and 1 mass $\% \mathrm{Sn}$. According to these figures, 1 mass $\%$ tin shifts slightly to higher temperatures both the stable and metastable eutectoid temperature ranges.

In most casting conditions, the cooling rate during the eutectoid transformation is such that substitutional solutes 
Table 2 Experimental tin, $\mathrm{k}_{\mathrm{Sn}}^{\mathrm{c} / \mathrm{L}}$, and silicon, $\mathrm{k}_{\mathrm{Si}}^{\mathrm{c} / \mathrm{L}}$, partition coefficient for equilibrium between austenite $\mathrm{c}$ and liquid $\mathrm{L}$ for various $\mathrm{Fe}-\mathrm{C}-\mathrm{Sn}$ and $\mathrm{Fe}-\mathrm{C}$ $\mathrm{Si}-\mathrm{Sn}$ alloys (compositions in mass $\%)^{[18]}$ and corresponding calculated values

\begin{tabular}{lccccc}
\hline Alloy & $\begin{array}{c}\text { Holding } \\
\text { temperature, } \mathrm{K}\end{array}$ & $\begin{array}{c}\text { Experimental } \\
\mathrm{k}_{\mathrm{Sn}}^{\mathrm{c} / \mathrm{L}}\end{array}$ & $\begin{array}{c}\text { Calculated } \\
\mathrm{k}_{\mathrm{Sn}}^{\mathrm{c} / \mathrm{L}}\end{array}$ & $\begin{array}{c}\text { Experimental } \\
\mathrm{k}_{\mathrm{Si}}^{\mathrm{c} / \mathrm{L}}\end{array}$ & $\begin{array}{c}\text { Calculated } \\
\mathrm{k}_{\mathrm{Si}}^{\mathrm{c} / \mathrm{L}}\end{array}$ \\
\hline Fe-4.02C-1.66Sn (a) & 1418 & 0.84 & 0.71 & & \\
Fe-3.58C-1.10Sn & 1485 & 0.63 & 0.52 & & \\
Fe-2.91C-1.03Sn (b) & 1586 & 0.42 & 0.34 & & \\
Fe-2.42C-1.64Sn (c) & 1613 & 0.37 & 0.30 & & 1.21 \\
Fe-3.92C-1.01-1.45Si (d) & 1426 & 0.58 & 0.62 & 1.22 & 1.08 \\
Fe-3.54C-1.53Sn-1.49Si (e) & 1484 & 0.46 & 0.50 & 1.20 & 0.92 \\
Fe-2.53C-1.37Sn-1.26Si & 1558 & 0.32 & 0.38 & 1.03 & 0.83 \\
Fe-2.07C-1.50Sn-1.41Si (f) & 1623 & 0.28 & 0.31 & 1.03 & \\
\hline
\end{tabular}

For calculation, either the temperature or the the alloy carbon content was changed as follows to ensure an austenite/liquid equilibrium: (a) $\mathrm{T}=1423 \mathrm{~K}$, (b) $\mathrm{w}_{\mathrm{C}}=2.6$ mass $\%$, (c) $\mathrm{w}_{\mathrm{C}}=2.3$ mass $\%$, (d) $\mathrm{T}=1431 \mathrm{~K}$, (e) $\mathrm{w}_{\mathrm{C}}=3.2$ mass $\%$ and (f) $\mathrm{w}_{\mathrm{C}}=1.8$ mass $\%$

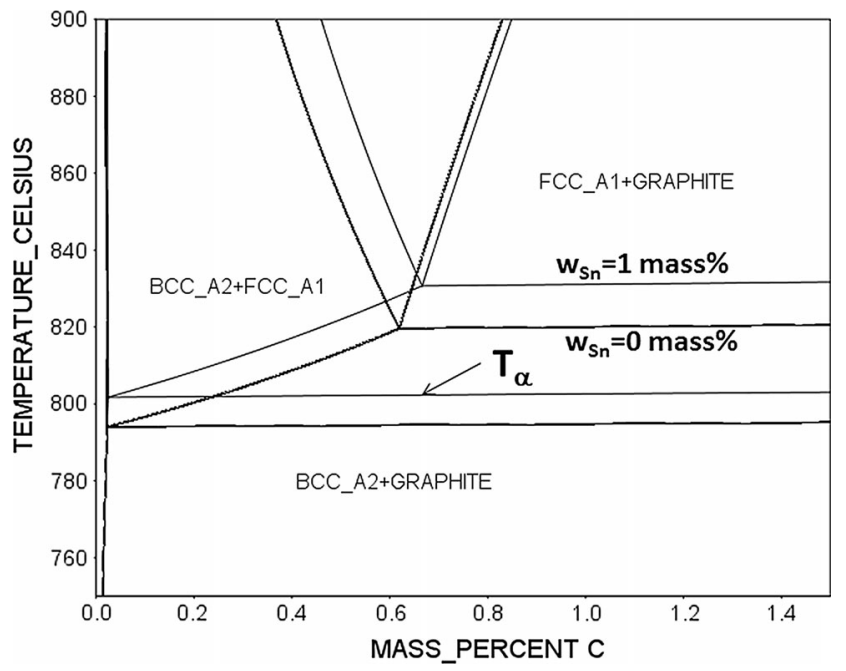

Fig. 3 Isopleth $\mathrm{Fe}-\mathrm{C}$ section of the stable $\mathrm{Fe}-\mathrm{C}-\mathrm{Si}-\mathrm{Sn}$ phase diagram at 2.5 mass \% Si and 0 and 1 mass $\% \mathrm{Sn}$ in the temperature range of the eutectoid transformation. The $\mathrm{T}_{\mathrm{a}}$ reference temperature for the alloy at 1 mass \% Sn is indicated with the arrow

cannot redistribute between ferrite and austenite (stable transformation) or pearlite and austenite (metastable transformation). Both transformations thus proceed with the product, either ferrite or pearlite, inheriting the content in substitutional solutes of the parent austenite. Accordingly, these transformations can well be described in a $\mathrm{Fe}-\mathrm{C}$ isopleth section of the relevant phase diagram, and it has been proposed that the upper temperature at which these transformations can proceed lies on the lower limit of the three-phase field. These growth conditions are similar to the case of para-equilibrium transfor-

mation as already described. ${ }^{[5,20]}$ The reference temperatures are denoted $T_{a}$ in the stable (Fig. 3) and $T_{p}$ in the metastable (Fig. 4) systems respectively as illustrated for the sections at 1 mass \% Sn.

The effect of $\mathrm{Sn}$ on the reference temperature for the stable and metastable eutectoid reactions is respectively of

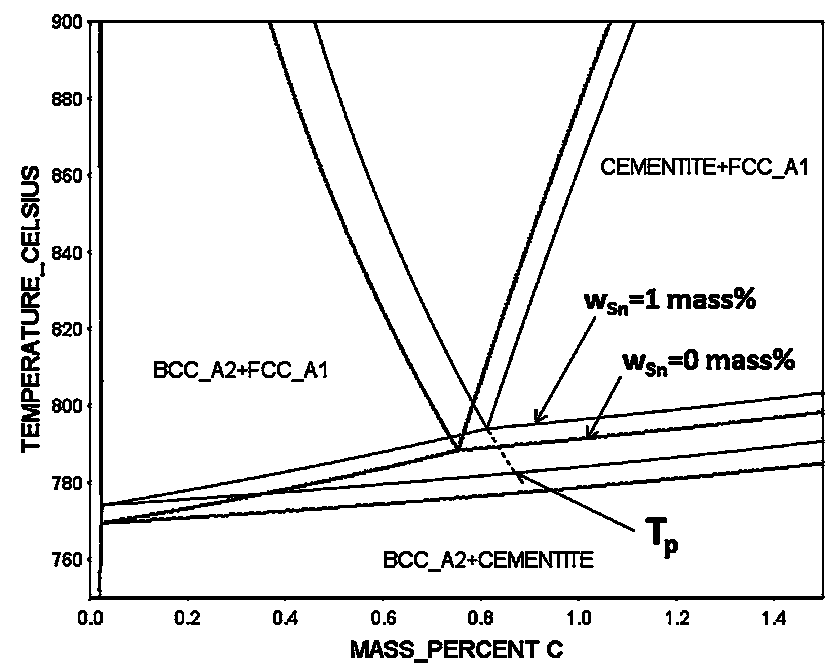

Fig. 4 Isopleth Fe-C section of the metastable Fe-C-Si-Sn phase diagram at 2.5 mass $\% \mathrm{Si}$ and 0 and $1 \mathrm{mass} \% \mathrm{Sn}$ in the temperature range of the eutectoid transformation. The $T_{p}$ reference temperature is assumed to be on the extrapolation of the c/a equilibrium line as indicated with the arrow for the alloy at 1 mass $\% \mathrm{Sn}$

?5.1 and $6.5 \mathrm{oC} / \mathrm{mass} \%$. These values are quite lower than the $21 \mathrm{oC} / \mathrm{mass} \%$ previously estimated on the basis of the comparison of the $\mathrm{Fe}-\mathrm{Si}$ and $\mathrm{Fe}-\mathrm{Sn}$ phase diagrams. ${ }^{[3]}$ The $T_{a}$ and $T_{p}$ reference temperatures have been previously expressed as function of composition based on phase diagram calculations. ${ }^{[21]}$ These expressions are here complemented with the effect of tin as:

$$
\begin{aligned}
& \mathrm{T}_{\mathrm{a}} 1 / 4739 \mathrm{p} 18: 4^{\circ} \mathrm{w}_{\mathrm{Si}} \mathrm{p} 2: 0^{\circ} \mathrm{\partial}_{\mathrm{Si}} \mathrm{P}^{2}-14: 0^{\circ} \mathrm{w}_{\mathrm{Cu}}-45: 0^{\circ} \mathrm{w}_{\mathrm{Mn}} \\
& \text { p 2:0 }{ }^{\circ} \mathrm{w}_{\mathrm{Mo}}-24: 0^{\circ} \mathrm{w}_{\mathrm{Cr}}-27: 5^{\circ} \mathrm{w}_{\mathrm{Ni}} \mathrm{p} 5: 1^{\circ} \mathrm{w}_{\mathrm{Sn}} \\
& \text { ठEq 4P } \\
& \mathrm{T}_{\mathrm{p}} 1 / 4727 \mathrm{p} 21: 6^{\circ} \mathrm{w}_{\mathrm{Si}} \mathrm{p} 0: 023^{\circ} \partial_{\mathrm{w}_{\mathrm{Si}}} \mathrm{P}^{2}-21: 0^{\circ} \mathrm{w}_{\mathrm{Cu}}-25: 0^{\circ} \mathrm{w}_{\mathrm{Mn}} \\
& \text { p 8:0 }{ }^{\circ} \mathrm{w}_{\mathrm{Mo}} \mathrm{p} 13: 0^{\circ} \mathrm{w}_{\mathrm{Cr}}-33: 0^{\circ} \mathrm{w}_{\mathrm{Ni}} \mathrm{p} 6: 5^{\circ} \mathrm{w}_{\mathrm{Sn}}
\end{aligned}
$$


Lacaze and Sertucha ${ }^{[3]}$ investigated alloys containing different amounts of copper and tin cooled at various rates in the solid-state range but all presenting a fully pearlitic structure. The compositions of these alloys are listed in Table 3 together with the calculated reference temperatures. For accounting for graphite precipitation, the $\mathrm{w}_{\mathrm{i}}$ values used for calculating these temperatures are the nominal contents listed in Table 3 multiplied by $1.05 .^{[5]}$

As the alloys presented a fully pearlitic structure, the experimental undercooling $\mathrm{DT}_{\mathrm{p}}=\mathrm{T}_{\mathrm{p}}-\mathrm{T}$ values, where $\mathrm{T}$ is the experimental temperature for the start of the eutectoid reaction, were evaluated as function of the cooling rate. These values are reported in Fig. 5 with symbols. Though scattered, the results show that $\mathrm{DT}_{\mathrm{p}}$ increases with increased cooling rate. Note that because of the experimental scattering, some of the values are negative for the lowest cooling rates. The most intriguing observation is that these results could be rationalized as extrapolating to a zero undercooling at a zero cooling rate. This is in strong contrast to results obtained with alloys containing no or a low amount of tin (less than 0.05 mass\%) for which the undercooling for the start of the pearlitic reaction could be extrapolated to a value of about $40 \mathrm{oC} .^{[4]}$ This previous extrapolation is shown with the interrupted line in Fig. 5 while the solid line was obtained by shifting it to a zero undercooling at zero cooling rate. It is seen that this solid line goes through the cloud of results for alloys containing more than 0.05 mass $\%$ of tin. This suggests that additions of tin at levels of 0.05 mass $\%$ or above suppresses the undercooling for pearlite formation, probably by decreasing efficiently the undercooling for cementite nucleation.

Figure 6 shows the so-called bull's eye structure obtained with a nodular cast iron that does not contain tin. Ferrite forms first and its growth is controlled by carbon diffusion from the parent austenite to the graphite nodules. The rate of this transformation decreases with time and temperature. On the contrary pearlite grows by redistribution between ferrite and cementite at the pearlite/austenite interface and its growth rate does not change with time though being temperature dependent. In Fig. 5 the change in the undercooling $\mathrm{DT}_{\mathrm{a}}=\mathrm{T}_{\mathrm{a}}-\mathrm{T}$ for the start of the ferritic reaction as measured on alloys with low level of

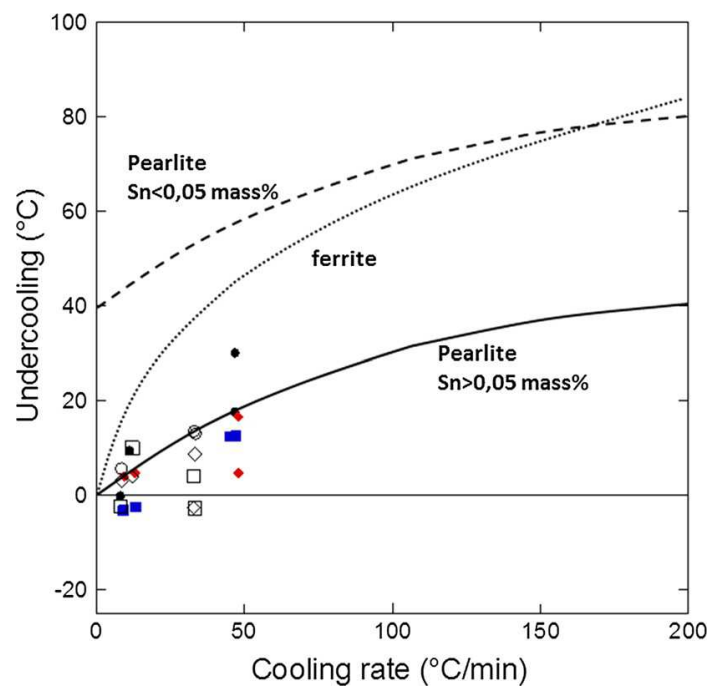

Fig. 5 Variation with cooling rate of the undercooling for the start of the pearlitic reaction. Symbols are experimental values obtained with the various alloys listed in Table 3. Interrupted and dotted lines show the correlation found on alloys with no or low level of tin for the pearlitic and ferritic reactions respectively. The solid line is the same as the interrupted line shifted to a zero undercooling at zero cooling rate

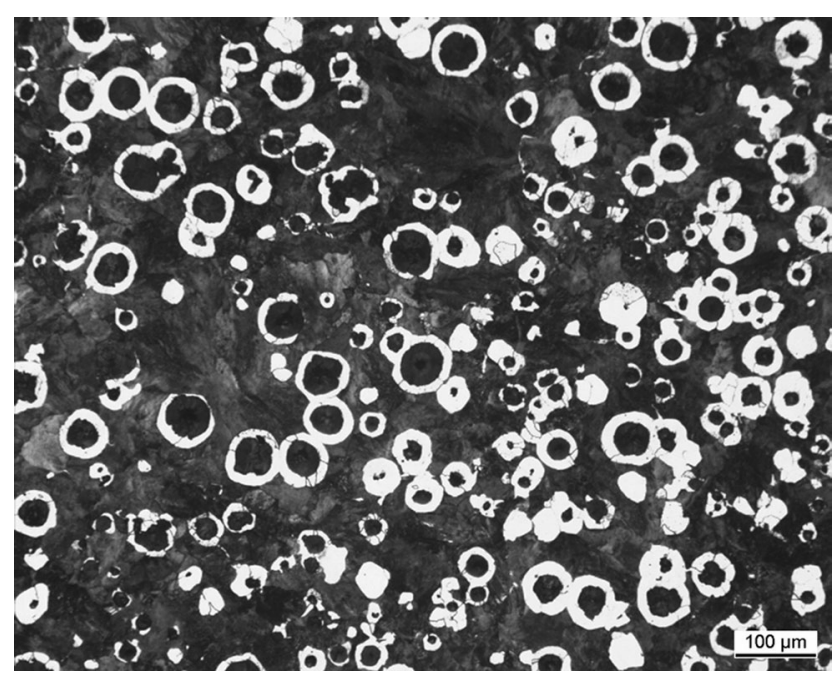

Fig. 6 Micrograph of a tin-free nodular cast iron showing a ferriticpearlitic matrix
Table 3 Nominal composition of the investigated alloys ${ }^{[3]}$ and calculated reference

temperatures for the stable $\left(\mathrm{T}_{\mathrm{a}}\right)$ and metastable $\left(\mathrm{T}_{\mathrm{p}}\right)$ reactions

\begin{tabular}{lccccccccccccc}
\hline Allov & $\mathrm{C}$ & $\mathrm{Si}$ & $\mathrm{Mn}$ & $\mathrm{P}$ & $\mathrm{S}$ & $\mathrm{Cu}$ & $\mathrm{Ti}$ & $\mathrm{Cr}$ & $\mathrm{Ni}$ & $\mathrm{Sn}$ & $\mathrm{Mg}$ & $\mathrm{T}_{\mathrm{a}}$ & $\mathrm{T}_{\mathrm{p}}$ \\
\hline 1 & 3.73 & 1.99 & 0.60 & 0.015 & 0.014 & 0.47 & 10.010 & 0.07 & 0.06 & 0.066 & 0.050 & 747.8 & 745.5 \\
2 & 3.73 & 2.03 & 0.58 & 0.014 & 0.018 & 0.68 & 0.036 & 0.07 & 0.06 & 0.042 & 0.055 & 746.6 & 742.1 \\
3 & 3.75 & 1.90 & 0.62 & 0.014 & 0.014 & 0.86 & 10.010 & 0.07 & 0.06 & 0.058 & 0.040 & 738.6 & 734.2 \\
4 & 3.87 & 2.07 & 0.62 & 0.020 & 0.020 & 0.32 & 10.010 & 0.07 & 0.07 & 0.095 & 0.060 & 751.2 & 749.9 \\
5 & 3.84 & 2.12 & 0.60 & 0.021 & 0.021 & 0.54 & 10.010 & 0.06 & 0.06 & 0.105 & 0.052 & 750.9 & 747.0 \\
6 & 3.83 & 2.04 & 0.60 & 0.018 & 0.019 & 0.71 & 10.010 & 0.07 & 0.06 & 0.105 & 0.052 & 745.9 & 741.6 \\
\hline
\end{tabular}


$\operatorname{tin}^{[4]}$ is also plotted with a dotted line. It is seen that the absolute value of this undercooling increases much more rapidly than that of the pearlitic reaction because of the differences in the growth mechanism involved in each reaction. The difference in sensitivity to cooling rate of the ferritic and pearlitic transformations is such that the slight difference between $T_{a}$ and $T_{p}$ for alloys listed in Table 3 could be overtaken at any finite cooling rate. This explains why a fully pearlitic matrix could be obtained with alloys containing more than 0.05 mass $\% \mathrm{Sn}$.

To emphasize the competition between stable and metastable phase transformations, the results in Fig. 5 have been plotted as a CCT-like diagram in Fig. 7. On the basis of Table 3 , the $T_{a}$ and $T_{p}$ temperatures have been set to 751 and $745 \mathrm{oC}$ respectively. The lines starting from $950 \mathrm{oC}$ are numbered with the corresponding cooling rate in $\mathrm{oC} / \mathrm{min}$. The curve labelled "Ferrite" and the two curves labelled "Pearlite" have been redrawn from Fig. 5 starting from $T_{a}$ and $T_{p}$ respectively. It is seen that the window for ferrite formation is large in case of alloys with low level of tin $(0.05 \mathrm{mass} \%)$ and that a cooling rate higher than $100 \mathrm{oC} /$ min is needed for reaching directly the pearlitic domain in this case. On the contrary, addition of tin moves the curve for pearlite appearance upwards to such an extent that the window for ferrite formation is practically limited to the temperature difference $T_{a}-T_{p}$. Traces of ferrite could thus be observed only at very low cooling rates, less than a few oC/min.

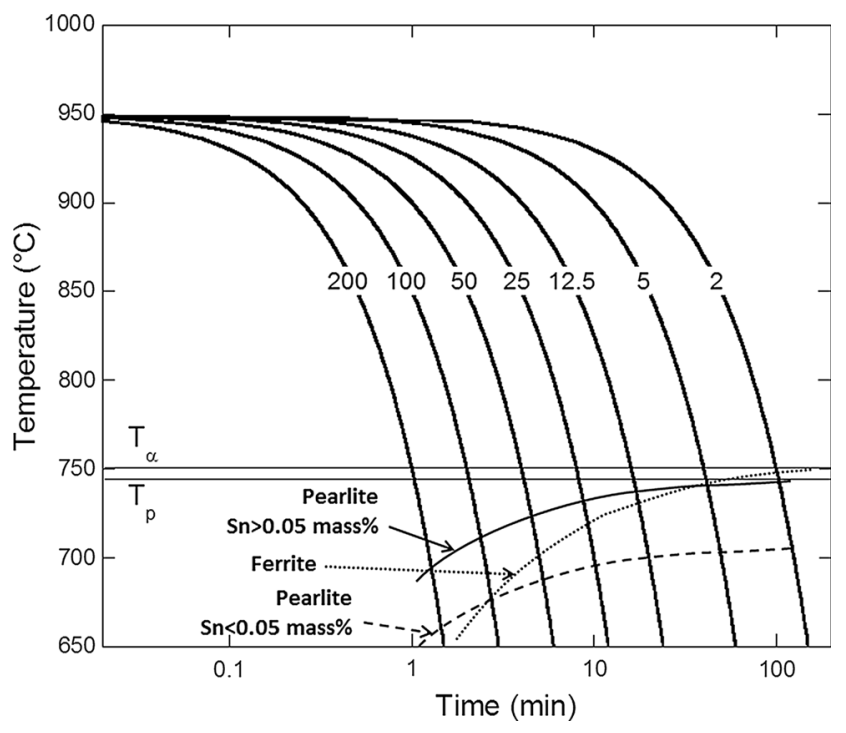

Fig. 7 Diagram illustrating the competition between ferrite and pearlite during continuous cooling from $950 \mathrm{oC}$. The lines starting from this temperature are numbered with the corresponding cooling rate in oC/min. The curve labelled "Ferrite" and the two curves labelled "Pearlite" have been redrawn from Fig. 5 starting from $\mathrm{T}_{\mathrm{a}}$ and $T_{p}$ respectively, they show the start of the respective transformation as detected by thermal analysis

\section{Discussion}

When the Sn content in the alloy is high enough, the above results suggest that nucleation of pearlite is facilitated to such an extent that any significant nucleation undercooling is unnecessary. This must relate to nucleation of cementite as it has been seen that ferrite forms without significant undercooling (see Fig. 5). In the introduction, it was mentioned that some authors found enrichment in $\mathrm{Sn}$ at the graphite/matrix interface which they proposed to be a barrier to carbon transfer to graphite or to lead to the formation of a Fe-Sn compound. It has to be stressed that $\mathrm{Sn}$ enrichment around graphite may not have occurred during solidification as it would have hindered the stable eutectic transformation. Accordingly, it should be assumed either that $\mathrm{Sn}$ segregated to this interface during solid state cooling or heat-treatment, or that it formed precipitates in solid state that would trigger cementite nucleation.

Duc et al. ${ }^{[22]}$ studied the phases forming at the interface between various $\mathrm{Fe}-\mathrm{C}$ alloys and liquid $\mathrm{Sn}$. According to these authors, the most likely compound to form at high carbon level is $\mathrm{Fe}_{3} \mathrm{SnC}$ and they reported this compound is stable between 540 and $935 \mathrm{oC}$ and forms easily from cementite. Accordingly, it may be assumed this compounds effectively forms in cast irons containing high enough $\mathrm{Sn}$. This formation will be easier close to graphite nodules and in the austenite field as this compound is an ordered form of austenite. These observations thus support the schematic of the formation of an intermediate $\mathrm{Fe}-\mathrm{C}-\mathrm{Sn}$ compound that triggers nucleation of cementite, somehow in line with conclusions by Lalich and Loper. ${ }^{[23]}$ This compound would eventually transform to cementite during final cooling of the alloys.

\section{Conclusion}

Without invoking any effect of tin on carbon diffusion in ferrite, the present analysis confirms that its pearlite promoting effect relates to a significant decrease of the driving force for pearlite appearance. This is most probably associated with a strong decrease of the driving force required for cementite nucleation as the formation of ferrite does not appear to need any significant undercooling. The exact mechanism for this effect could possibly be related to tin segregation at the graphite/austenite interface as reported by Johnson and Kovacs ${ }^{[6]}$ for spheroidal graphite irons. However, contrarily to the statement by Kovacs, ${ }^{[7]}$ this segregation may not have developed during solidification as it would have hindered eutectic transformation in the stable system. The most probable mechanism is the transient formation of a $\mathrm{Fe}_{3} \mathrm{SnC}$ compound at the interface between graphite and austenite during cooling after 
solidification. This compound presents an ordered FCC structure and has been found to easily transform to cementite. $^{[22]}$

\section{References}

1. L. Guerin and M. Gagné, Effect of $\mathrm{Mn}, \mathrm{Cu}$ and $\mathrm{Sn}$ on the Microstructure and Properties of Ductile Iron Castings, Foundryman, 1987, 80, p 334-336

2. J. Lacaze, J. Sertucha, P. Larrañaga, and R. Suárez, Combined Effects of Copper and Tin at Intermediate Level of Manganese on the Structure and Properties of as-Cast Spheroidal Graphite Cast Iron, Arch. Metall. Mater., 2017, 62, p 833-839

3. J. Lacaze and J. Sertucha, Effect of $\mathrm{Cu}, \mathrm{Mn}$ and $\mathrm{Sn}$ on Pearlite Growth Kinetics in as-Cast Ductile Irons, Int. J. Cast Metals Res., 2016, 29, p 74-78

4. J. Sertucha, P. Larrañaga, J. Lacaze, and M. Insausti, Experimental Investigation on the Effect of Copper Upon Eutectoid Transformation of as-Cast and Austenitized Spheroidal Graphite Cast Iron, Int. J. Metalcasting Winter, 2010, 4, p 51-58

5. J. Lacaze, The Austenite to Pearlite/Ferrite Transformation, ASM Handbook, Vol 1A, 2017, (to appear).

6. W.C. Johnson and B.V. Kovacs, The Effect of Additives on the Eutectoid Transformation of Ductile Iron, Metall. Trans. A, 1978, 9, p 219-229

7. B.V. Kovacs, Pearlite Stabilization in Cast Irons, AFS Trans., 1980, 88, p 79-96

8. V.K. Grigorovich, Influence of Alloying Elements on Cementite Stability and the Graphitization of Cast Irons, Russ. Cast. Product., 1964, 12, p 557-561

9. E.N. Pan, M.S. Lou, and C.R. Loper, Effects of $\mathrm{Cu}, \mathrm{Sn}$, and $\mathrm{Mn}$ on the Eutectoid Transformation of Graphitic Cast Irons, AFS. Trans., 1987, 95, p 819-840

10. K.C. Hari Kumar, P. Wollants, and L. Delaey, Thermodynamic Evaluation of Fe-Sn Phase Diagram, CALPHAD, 1996, 20, p 139149

11. J. Miettinen, Reassessed Thermodynamic Solution Phase Data for Ternary Fe-Si-C System, CALPHAD, 1998, 22, p 231-256
12. J. Lacaze and B. Sundman, An Assessment of the Fe-C-Si System, Metall. Trans. A, 1991, 22, p 2211-2223

13. H. Nowotny, Strukturchemie Einiger Verbindungen Der Ubergangsmetalle Mit Den Elementen C, Si, Ge, Sn, Phys. Solid State Chem. 5, 1971, 27-70, (in German) (abstract in English).

14. H.H. Stadelmaier and L.J. Huetter, Ternary Carbides of the Transition Metals Nickel, Cobalt, Iron, Manganese with Zinc and Tin, Acta Metal., 1959, 7, p 415-419

15. D. Connetable, J. Lacaze, P. Maugis, and B. Sundman, A Calphad Assessment of Al-C-Fe System with the $\mathbf{j}$ Carbide Modelled as an Ordered Form of the fcc Phase, CALPHAD, 2008, 32, p 361370

16. Z. Wang, L. Wang, and T. Du, Study of the Thermodynamic Properties of Fe-C-Sn, Fe-C-Pb, Fe-C-Pb-Ce Liquid Solutions, J. Iron Steel Res. Suppl., 1987, 7, p 99-106, (in Chinese) (abstract in English).

17. N. Imai, T. Tanaka, T. Yuki, T. Iida, and Z.I. Morita, Equilibrium Distribution of Sn Between Solid and Liquid Phases in Fe-Sn and Fe-C-Sn alloys, ISIJ, 1991, 77, p 38-44, (in Japanese) (abstract in English).

18. T. Tanaka, Ph.D. thesis, Thermodynamics of the Equilibrium Distribution of Solute Elements Between Solid and Liquid Phases in Iron Alloys, Osaka University Knowledge Archive, 1984.

19. T. Kanno, T. Kikuchi, and I. Kang, Effect of Alloying Elements on the Eutectic Temperatures in Cast Iron, AFS Trans., 2005, paper 05-203.

20. J. Lacaze, C. Wilson, and C. Back, Experimental Study of the Eutectoid Transformation in Spheroidal Graphite Cast Iron, Scand. J. Metall., 1994, 23, p 151-163

21. V. Gerval and J. Lacaze, Critical Temperatures of Spheroidal Graphite Cast Irons: A Review of Literature Data, ISIJ Int., 2000, 40, p 386-392

22. D. Duc, D. Treheux, P. Guiraldenq, B. Lambert, and P. Poyet, Influence du Carbone sur les Structures d'Equilibre du Diagramme Fer-Etain, Application à l'Etude de l'Influence de l'Etain sur la Transformation Perlitique dans les Fontes, Fonderie, 1973, 321, p 89-97

23. M.J. Lalich and C.R. Loper, Effects of Pearlite-Promoting Elements on the Kinetics of the Eutectoid Transformation in Ductile Cast Irons, AFS Trans., 1973, 81, p 217-228 